PRIMARY CARE:

CLINICS IN

Prim Care Clin Office Pract

OFFICE PRACTICE

32 (2005) xi-xiv

\title{
Preface
}

\section{Care of the Older Adult in the Office Setting}

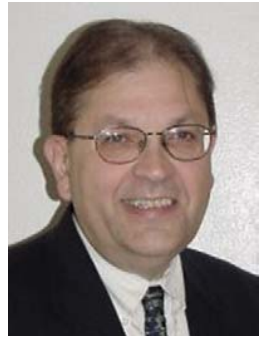

Larry Lawhorne, MD

Guest Editor

The aging of America is upon us. For decades, health care providers gave little attention to the tables and graphs showing the shifting age distribution of the US population while alarmists made dire predictions. But now, with the realization that the first of the baby boom generation will turn 65 years old in just 6 years, the contents of the tables and the trajectories displayed on the graphs give all of us a sense of urgency. The number of Americans aged 65 years and older has grown from 3.1 million in 1900 to almost 36 million today, and is projected to be 71.5 million in 2030. Even more impressive is the number of Americans aged 85 years and over: 4 million today and projected to reach 20 million by 2050 .

Many believe that our health care and fiscal systems are not prepared to manage this dramatic growth in the number of older adults. Current analyses suggest that $5 \%$ of Medicare beneficiaries consume $50 \%$ of Medicare dollars and that many of the high consumers are frail. In addition, there is a shift from acute care needs to chronic care needs, putting many older adults in the waiting rooms of office-based primary care physicians. Already, office visits by older adults make up about $40 \%$ of the typical internist's practice, whereas $25 \%$ of visits to family physicians are made by people over age 65 years.

Ideal care for the frail elderly may be envisioned as being delivered by a geriatrician and a fine-tuned interdisciplinary team, but this scenario is unlikely to unfold for at least two reasons. First, the cost would be 
prohibitive and second, there would not be enough geriatricians to do the work. Today there are about 7,600 physicians with a Certificate of Added Qualification in Geriatric Medicine in the face of an estimated need for 20,000 . Approximately 36,000 geriatricians will be needed by 2030 , but the actual number will probably fall far short. This shortfall will place the chronic care of the older adult in the hands of internists, family physicians, nurse practitioners, and physician assistants. As front-line providers in the care of the elderly, these clinicians will need to develop skills in assessment and management of multiple chronic conditions in a single individual and in the recognition, assessment, and management of geriatric syndromes such as falls, urinary incontinence, and dementia. A shift from a diseasedriven approach to one that focuses on function and quality of life may be necessary to provide the best care. The office milieu must also allow ample opportunity for the older adult to craft his or her advance care directive.

Although all of this may seem overwhelming, much of what needs to be done comes down to doing simple things consistently and well:

- Ask periodically about key areas of function.

- Ask about falls or fear of falling.

- Ask about urinary incontinence.

- Review the medication list, including prescription drugs, over-thecounter drugs, and herbal preparations; eliminate the ones that no longer have a favorable benefit-to-risk profile.

- Ask about appetite.

- Ask about losses.

- Obtain accurate weights and measure supine and standing blood pressures at every office visit.

- Administer screening and diagnostic tests in an incremental fashion based on what is learned by doing these simple things.

This issue of the Primary Care: Clinics in Office Practice is designed to guide the reader through the process of incremental functional assessment suited for the primary care office rather than comprehensive geriatric assessment conducted by a geriatrician and an interdisciplinary team. The first two articles set the stage by providing general comments on the approach to the office care of the older adult and by describing the process of incremental functional assessment. The third article delves into the area of shared decision making because of its importance to much of what follows.

The articles on nutrition and community resources supplement the article on incremental functional assessment. Two common geriatric syndromesfalls and urinary incontinence-are covered next. Injurious falls, especially those that result in hip fractures can be deadly, so reducing fall risk becomes 
paramount. Urinary incontinence is so common as to be considered trivial or even normal, but its affect on quality of life is far from trivial.

Hypertension is emerging as a major health concern among older adults and may even be a risk factor for late-life depression. Gone are the days when an acceptable systolic blood pressure was equal to 100 plus the age of the patient. The judicious use of the prescription pad is a key factor in providing good geriatric care. Reconciling best practices in pharmacotherapy with the bugbear of polypharmacy is addressed in the ninth article.

The last three articles deal with depression, nursing facility care, and endof-life care. A most difficult task for the office-based physician is interpreting the meaning of depressive symptoms. Depressive symptoms may indicate that the person is experiencing a major depressive episode but may also be associated with bereavement, loneliness, a medical condition, or the natural disengagement that sometimes occurs near the end of life. What role should the office-based clinician play in the care of his or her patient who enters a nursing facility? If there is a role, how can good nursing facility care be incorporated into an already busy office practice? Finally, clinicians who have the responsibility and privilege of providing care for older adults should become skilled in end-of-life care. As with other aspects of care, good end-of-life care means doing the simple things consistently and well. Communicating with the person who is dying and with family and friends is time-consuming but rewarding. Anticipating and addressing pain and other common end-of-life symptoms are skills that can easily be added to the repertoire of the office-based clinician.

Office-based clinicians are ideally positioned to coordinate the care of older Americans. The skills needed to do it are easily honed, but the time required to do it right is in short supply. In addition, the current Medicare reimbursement system does not appropriately value the care-coordinating activity that can be so important in helping an older adult maintain function and achieve an acceptable quality of life.

As we approach 2011, it can be said that the future is now. Most officebased primary care clinicians will step forward to provide exemplary care for America's aging population. Health care economists and policy makers must also step forward. The executive and legislative branches at state and federal levels must work in a bipartisan way to give Medicare beneficiaries and the health care providers who serve them a health plan that emphasizes function, quality of life, and patient self-determination.

\section{Acknowledgments}

Doctors Lawhorne and Ensberg wish to dedicate the article on incremental assessment to Dr. Joseph Papsidero (1929-2000) who was both mentor and friend. We also wish to acknowledge the Bureau of Health 
Professions (U. S. Department of Health and Human Services) for supporting the work of the Geriatric Education Center of Michigan.

Larry Lawhorne, MD

Department of Family Practice Geriatric Education Center of Michigan

College of Human Medicine

Michigan State University B 215 West Fee Hall

East Lansing, MI 48824, USA

E-mail address: larry.lawhorne@hc.msu.edu 